\title{
Modality, concreteness, and set-size effects in a free reconstruction of order task
}

\author{
IAN NEATH \\ Purdue University, West Lafayette, Indiana
}

\begin{abstract}
Would informing subjects which items were presented on the current list remove effects of presentation modality, concreteness, and set size in a long-term free reconstruction of order task? In Experiment 1, a typical modality effect was found: memory for the final item in a list was enhanced when the item was presented auditorily rather than visually. In Experiment 2, order memory was better for concrete than for abstract items. And in Experiment 3, order memory was better when the same six items were presented on every trial than when a unique set of six items was presented. In all conditions in all experiments, the to-be-remembered items were given to the subject at test. These results suggest that contrary to a popular assumption, the reconstruction of order task does not provide a functionally pure measure of order memory.
\end{abstract}

Accurately reproducing the order of a list of items or set of events requires remembering two different kinds of information: information about the identity of each item, and information about the presentation order (Crowder, 1976; Healy, 1974). In the typical recall task, such as serial recall, these two sources of information are confounded and cannot be easily separated. In an attempt to eliminate such confounds, some researchers have adopted a task known as reconstruction of order (e.g., Healy, Fendrich, Cunningham, \& Till, 1987; Nairne, 1991, 1992; Nairne \& Neumann, 1993).

In this task, a series of items is presented, and at test the same items are presented again, either in a new random order or in alphabetical order. Presumably, all relevant item information is available to the subject, who is now free to indicate the original presentation order. Typically, subjects are free to reconstruct the order in any manner they choose; for example, a subject might choose to indicate which item occurred in Position 5 first, and then indicate which item occurred in Position 1 second, and so forth. This free reconstruction of order task may be contrasted with serial reconstruction of order, which requires the subject to indicate which item occurred in Position 1 first, which item occurred in Position 2 second, and so on. Because all necessary item information is given to the subject at the time of test, the free reconstruction of order task "is typically seen as a pure test of position or order memory" (Whiteman, Nairne, \& Serra, 1994, p. 276). The three experiments reported here demonstrate that functionally a free reconstruction of order task is not necessarily a pure measure of order memory: Even when subjects are informed of the

I thank Aimée M. Surprenant for comments on an earlier version of this manuscript, James S. Nairne for insightful discussions, and G. A. Bernardin, David Charleston, Chris Nethercut, Barbara Ordela, and Tammy Patsel for testing subjects. Correspondence may be addressed to I. Neath, 1364 Psychological Sciences Building, Purdue University, West Lafayette, IN 47907-1364 (e-mail: neath@psych.purdue.edu) exact set of items for the current trial, modality, concreteness, and set size effects, which are presumed to be due to differences in item information, still obtain.

Free reconstruction of order can be seen as a detailed recognition judgment. As Crowder (1976) noted, a recognition judgment requires answering the question, Did this item appear on this list? A reconstruction of order task requires answering a similar, albeit more detailed, question, Where did this item appear on this list? The assumption that free reconstruction of order tasks affords a pure measure of position or order information is similar to an assumption made concerning standard recognition tests. For example, in most forms of generate-recognize theory (e.g., Anderson \& Bower, 1972; Bahrick, 1970; Kintsch, 1970 ), it was assumed that to recall an item, the subject first had to generate a set of candidates and then had to perform a recognition judgment before actually producing any response. In a recognition test, the first phase was not necessary. For example, Greene, Elliott, and Smith (1988, p. 569) have argued that when the availability of item information is controlled by using recognition tests, the subjects have the items provided by the experimenter and thus do not have to generate the items themselves.

The flaw in this logic is the assumption that the item itself is always the best retrieval cue. For example, words can be recalled even when they cannot be recognized (Tulving, 1983, chap. 13), a finding that led to the abandonment of the generate-recognize models (M. J. Watkins \& Gardiner, 1979). Moreover, many established context effects can be observed with a recognition procedure (Tulving, 1983, chap. 11) even when the meaning of the item is not changed (Feenan \& Snodgrass, 1990). For example, Geiselman and Glenny (1977) found better recognition performance when the same voice pronounced the item at study and test than when a different voice pronounced the item at test. Presumably, this is because presenting an item to the subject does not always enable the subject to form the correct internal representation. 
Capaldi and Neath (1995) have argued that all tests of memory require the comparison of an internal representation with an external cue - a process similar to Tulving's (1983) conception of synergistic ecphory - and provide substantial evidence from both the animal and human literatures in support of this view. Although free reconstruction of order tasks were not explicitly considered, Capaldi and Neath found no substantive evidence against the view that memory is best characterized as a discrimination problem that involves both an external cue and an internal representation.

The three experiments reported here suggest that functionally the free reconstruction of order task is not necessarily a pure measure of position or order memory because at test the subject performs a discrimination based on both external information and an internal representation. This representation, it is argued, must necessarily contain item information. Rather than saying that reconstruction of order tasks are unique, I argue that these tests require a similar discrimination process as that for other memory tests. If the subject has to compare an internal representation that includes item information, then variables that affect item information, such as modality, concreteness, and set size, should affect free reconstruction of order tests. If, on the other hand, free reconstruction of order tasks are unique in affording a functionally pure measure of order information, as some theorists assume, these variables should have no effect on performance.

\section{EXPERIMENT 1}

The modality effect describes the enhanced memory for items at the end of list when the items are presented auditorily rather than visually (Corballis, 1966; Murray, 1966; Washburn, 1916). When this effect occurs in a list that includes distractor activity after every item - the continual distractor paradigm-it is known as the longterm modality effect (e.g., Gardiner \& Gregg, 1979). Under appropriate conditions, the modality effect is found with both free and serial recall, and with both betweenand within-subjects designs (see Penney, 1989, for a review). Experiment $I$ was designed to see whether the modality effect would obtain in a long-term free reconstruction of order task.

Both major accounts of modality effects, Glenberg's (1987) temporal distinctiveness theory and Nairne's (1990) feature model, predict that no modality effect will be observed in a free reconstruction of order task if the task is a pure measure of order information. ${ }^{1}$ Both views characterize retrieval as a discrimination process in which the subject attempts to discriminate a potential target item from other items. Moreover, both emphasize the relative, rather than absolute, nature of this discrimination. It is the discrimination process that leads to the modality effect, and if this phase is removed by presenting the items to the subjects, there should be no auditory advantage at the end of the list.

In Experiment 1, subjects read five letters either aloud or silently. Many researchers who use reconstruction of order use a verbal distractor task, such as reading digits out loud. To avoid the potential influence of other verbal processes, the distractor task in Experiment 1 was adopted from a procedure used by M. J. Watkins, LeCompte, Elliott, and Fish (1992). Between presentation of each tobe-remembered item, there was an auditory or visual signal. Each signal lasted 250, 500,1,000, or 2,000 msec, and these four signals formed a temporal pattern. Thus, each subject saw a letter, which was read aloud or silently, and then saw or heard a signal that lasted between 250 and $2,000 \mathrm{msec}$. Then, the next letter was presented, followed by another signal. Half of the time, subjects were asked to reconstruct the presentation order of the five letters, and half the time, subjects were asked to tap back the temporal pattern marked by the signals, preserving the temporal rhythm. Subjects did not know until after list presentation which test would occur. If performance on the distractor task is similar for the auditory and visual groups, it rules out the possibility that subjects were differentially allocating their resources. In addition, because modality of the distractor task was manipulated, it provides an opportunity to rule out the possibility that one type of distractor task is more detrimental to performance than the other. Finally, because the task is not verbal, it minimizes the possibility of verbal interference between the distractor task and the to-be-remembered letters.

\section{Method}

Subjects. Forty-four Purdue University undergraduates volunteered to participate in exchange for credit in introductory psychology courses.

Materials. The to-be-remembered items came from a pool of 18 letters ( $a, e, i, o, q, u, w$, and y excluded). The two signals that marked the temporal pattern were a $1000-\mathrm{Hz}$ sine-wave tone and a gray rectangle. Each signal was presented for $250,500,1,000$, or $2,000 \mathrm{msec}$, which resulted in four different patterns. Pattern 1 had four signals lasting 250,500, 1,000, and 2,500 msec; Pattern 2 was 500, 2,500, $250,1,000$; Pattern 3 was $1,000,250,2,500,500$; and Pattern 4 was $2,500,1,000,500$, and 250. All stimuli were presented on, and all responses were collected by, an Apple Macintosh LC computer.

Design. Modality of the to-be-remembered items was a betweensubjects factor, and both modality of the signals and serial position were within-subjects factors. Subjects in the visual group read the letters silently, whereas those in the auditory group pronounced the names of the letters out loud. Vocalized information produces essentially the same effects as does pure auditory information (Crowder, 1970). Each list contained five different letters randomly drawn from the pool, and each letter was displayed for $500 \mathrm{msec}$. Between the offset of one letter and the onset of the next letter, a signal was presented. The signal was a gray rectangle or a $1000-\mathrm{Hz}$ tone. Immediately after the offset of the fifth letter, one of two tests occurred. For the free reconstruction of order test, 10 buttons appeared on the screen, 5 displaying the letters that had appeared on that trial in alphabetical order and 5 displaying the numbers $1-5$. The subject's task was first to click on any of the 5 "letter" buttons and then to click on one of the "number" buttons to indicate which position the letter had originally appeared in. It was emphasized to the subjects that they could click on these buttons in any order. The subject's responses were displayed on the screen, but the subjects were not told whether they had made the correct response. The pattern test required the subject to tap back the temporal pattern marked by the signals by pressing the button on the mouse in the correct rhythmic pattern. For this test, the subject needed to press the mouse button five times to mark the four intervals in the pattern. It was empha- 
sized to the subjects that to be accurate on this task, they had to leave the same amount of time between taps as the temporal duration of the appropriate signal. Twenty seconds were allowed for both tests.

Procedure. The subjects were informed that we were interested in how well they could perform several tasks simultaneously. One task was to reconstruct the order in which they saw five letters. The other task was described as tapping back a rhythmic pattern using the mouse button. The subjects practiced each task prior to the experimental trials, and none reported any difficulty with either test. Each subject received 2 practice lists, one of each type of test, and then 80 experimental trials, 40 testing order memory and 40 testing temporal memory. Of each set of 40 , half used visual signals and half used auditory signals. Each subject received a new, different random order of trials. The subjects were permitted to take a short break approximately halfway through, and they could adjust the monitor and volume to comfortable levels. The subjects were tested individually, and an experimenter ensured compliance with the instructions.

\section{Results}

Distractor task performance. The data from the temporal pattern task were scored using the method described in detail by M. J. Watkins et al. (1992). For both target and response sequences, the proportion of the total duration of the whole sequence consumed by each signal was computed, and the sum of the absolute value of the difference between target and response proportions constituted the error score. Figure 1 shows the mean error scores in reproducing the temporal pattern as a function of the modality of the signal and the modality of the tobe-remembered item.

Subjects reproduced the temporal pattern equally well when the signal was auditory (a mean error score of .073) as when it was visual $(.072)$. Furthermore, the modality of the to-be-remembered items did not affect performance, with mean errors of .071 for the auditory and .074 for the visual condition. Although performance on Pattern 1 (.092) was reliably less accurate than performance on the other three patterns $[.063, .070$, and .066 for Patterns 2 , 3 , and 4 respectively; $F(3,126)=86.48, p<.01]$, this

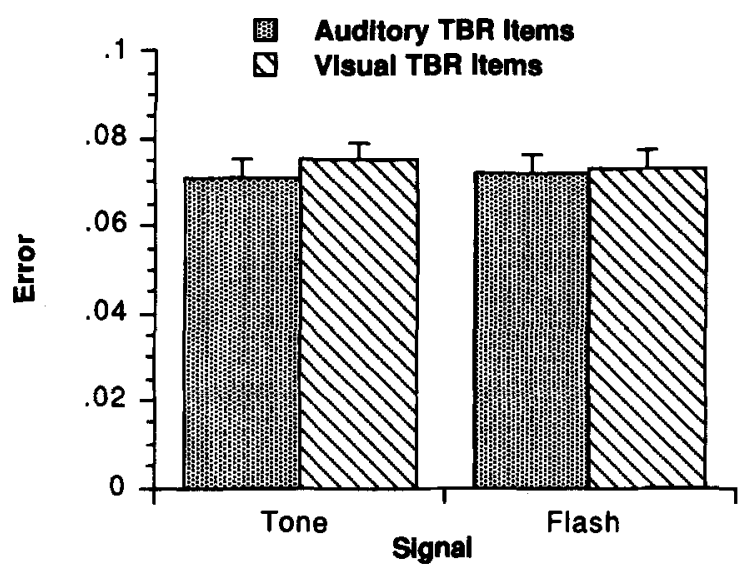

Figure 1. Errors (and standard error of the mean) in reproducing the temporal patterns as a function of modality of the tobe-remembered (auditory or visual) items and signal modality (tone or flash) from Experiment 1. See the text for how the error scores were computed. did not interact with any other variable. ${ }^{2}$ Even though the experiment was sufficiently sensitive to detect differences in performance as a function of pattern, it detected no differences as a function of modality.

These data replicate the major finding of M. J. Watkins et al. (1992). They found an auditory advantage in reproducing a temporal pattern only when (1) subjects mouthed an irrelevant item throughout presentation of the sequences and (2) the sequences comprised repetitions of just one signal. In other words, when subjects saw different signals or were not mouthing an irrelevant item, there was no evidence of better memory for the temporal pattern when the signals were auditory than when they were visual. In this experiment, neither the modality of the signals nor the modality of the to-be-remembered items affected the accuracy with which subjects reproduced a temporal pattern. These findings add to a growing number of studies that show no modality difference when temporal information is manipulated (e.g., Crowder \& Greene, 1987; Neath \& Crowder, 1990; Schab \& Crowder, 1989).

Order reconstruction. On those trials when a free reconstruction of order test was administered, there was no difference between the overall proportion of items ordered correctly in the auditory condition (.636) and the visual condition $[.618 ; F(1,42)<1]$. However, as Figure 2 shows, even when all of the to-be-remembered items are given to the subject at test, there is still a robust modality effect that resembles the auditory advantage seen in serial recall tests. Performance at the final serial position was reliably more accurate in the auditory than in the visual condition (.638 vs .439).

There was a reliable effect of serial position $[F(4,168)=$ $\left.27.56, M S_{\mathrm{e}}=0.039, p<.01\right]$, reflecting the basic serial position curve, and there was a reliable interaction between the modality of the to-be-remembered items and serial position $\left[F(4,168)=5.52, M S_{\mathrm{e}}=0.039, p<.01\right]$, reflecting the standard modality effect. Importantly, the modality of the distractor task did not systematically affect performance on the reconstruction of order task for one group or the other. Although the modality of the signal did have a small effect on reconstruction accuracy $\left[F(1,42)=5.36, M S_{\mathrm{e}}=0.021, p<.05\right]$, with fewer letters being ordered correctly when the signal was a tone (.611) than when it was a flash (.643), it did not interact with the modality of the to-be-remembered items $[F(1,42)$ $\left.=2.76, M S_{\mathrm{e}}=0.021, p>.10\right]$ or with serial position $[F(4,168)<1]$. The three-way interaction was not reliable $\left[F(4,168)=1.43, M S_{\mathrm{e}}=0.007, p>.20\right]$.

\section{Discussion}

Both major accounts of modality effects - Glenberg's (1987) temporal distinctiveness theory and Nairne's (1990) feature model - predict that modality effects will obtain in a long-term free reconstruction of order task only if the task is not a pure measure of order information. Both views state that the modality effect arises as a result of the process whereby subjects attempt to determine which items were on the list. 


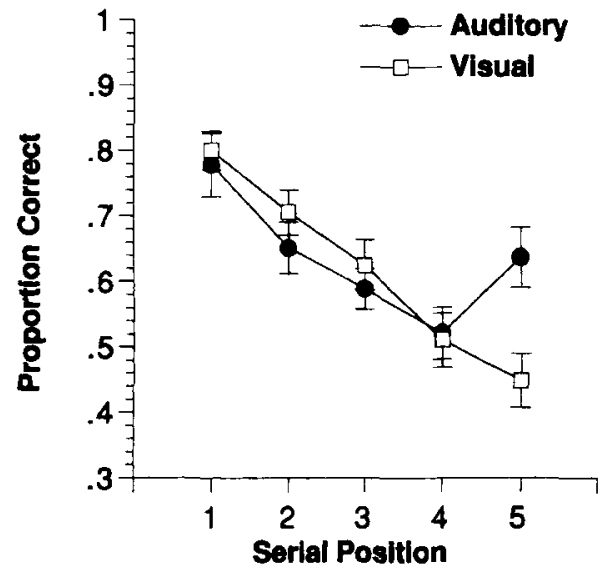

Figure 2. Proportion of letters (and standard error of the mean) correctly placed in their presentation order as a function of modality of presentation and serial position in Experiment 1.

In Glenberg's (1987) temporal distinctiveness theory, recall involves the construction of temporally defined search sets. The memory representation of each list item carries an associated "consistency function," a distribution of evidence that a particular item has occurred at a particular time. These functions center on the actual times of occurrence but overlap with nearby distributions to some extent. Glenberg assumes that recall requires construction of search sets that contact a particular temporal region. Recall of an item from the list is a positive function of the degree of overlap between the temporal region defined by the search set and the consistency function associated with the item. However, recall is also assumed to be inversely related to the number of items contacted by the search set. As retrieval is delayed, search sets are assumed to spread, thereby including a more extended temporal region and contacting an increasing number of items. Because the consistency functions are more flat for visually presented items and less flat for auditory items, more visual items will tend to be contacted by each search set, with a corresponding decrease in the probability of recall of those items, compared with auditory items.

Nairne's (1990) feature model assumes, following O.C. Watkins and M. J. Watkins (1980; see also Penney, 1989), that echoic and nonechoic representations of an item can be viewed as different 2 spects (or features) of a common memory trace. Items in memory contain both modalitydependent features (information about the conditions of presentation) and modality-independent features (information that arises through the cognitive processes of identification and categorization). Individual features can be overwritten if successive items are similar, and this overwriting degrades the identity of the traces in primary memory. Recall depends primarily on the match between a degraded trace in primary memory and a particular undegraded trace in secondary memory. It is not the loss of trace information per se that lowers recall, but rather the reduction in similarity of a given degraded trace to its undegraded trace relative to the similarity of the other items to the same trace. The difference between a visual item and an auditory item is that the latter will convey more modality-dependent information than the former; modality-independent information is presumed to be the same, regardless of the mode of presentation. To the extent that the modality-dependent information is useful in distinguishing one trace from another, performance will be better in an auditory than in a visual condition. In serial recall, for example, this additional differentiating information will typically benefit only the final item, because the modality-dependent information of earlier items will have been overwritten. If the modality-dependent information is not useful in distinguishing items, as with auditory presentation of homophones (Crowder, 1978b), there will be no modality effect.

Experiment 1 clearly shows that the modality effect seen with long-term free reconstruction of order is similar to that seen with immediate serial recall. According to both major explanations of the modality effect, this implies that item information was not fully reinstated by presenting the items at test. Subjects were still performing judgments based on item discrimination, and this led to the advantage for auditory items at the end of the list. Analyses of performance on the distractor task ruled out any explanation based on differential processing by one group or any explanation based on selective interference between the modality of the distractor task and the modality of the to-be-remembered items. The goal of Experiment 2 was to see whether another variable that affects item information also would affect performance on the reconstruction of order task.

\section{EXPERIMENT 2}

In the typical memory task, concrete words are recalled better than abstract words (Crowder, 1976). A common explanation is that the advantage that accrues to concrete words occurs because they have more forms of representation (e.g., Paivio, 1969) or because they are associated with more items in semantic memory (e.g., Jones, 1988). Both views, however, imply that concrete words are easier to generate than abstract words. If presenting the to-be-remembered items at test does constitute a pure test of order memory, there should not be a benefit for the concrete words. In Experiment 2, therefore, abstract and concrete items were presented to the subject in a longterm free reconstruction of order task. Modality of presentation was also varied, to ensure that the modality effect observed in Experiment 1 was not confined to a particular set of stimuli or presentation conditions. For the same reasons, the distractor task was changed to verifying addition problems, a task that is more often used in studies of the long-term modality effect, and list length was increased.

\section{Method}

Subjects. Eighty-eight different Purdue University undergraduates volunteered to participate in exchange for credit in introductory psychology courses. 
Materials. A pool of 207 concrete and 204 abstract nouns were selected from the Paivio, Yuille, and Madigan (1968) norms. On a scale of 1 (lowest) to 7 (highest), the concrete words had a mean concreteness rating of 6.52 (maximum 6.90 , minimum 6.27 ) and a mean imageability rating of 6.83 (maximum 7.00 , minimum 6.34). The abstract words had a mean concreteness rating of 3.11 (maximum 4.00 , minimum 1.77 ) and a mean imageability rating of 2.54 (maximum 4.00, minimum 1.18). Both pools of words had the same mean word frequency, 41.07 , although the standard deviation was larger for the abstract pool than for the concrete pool (70.84 vs. $47.57)$. When the exact word frequency was not specified in Paivio et al. (1968), the value from Kučera and Francis (1967) was used. All stimuli were presented on, and responses recorded by, a Macintosh $\mathrm{LC}$ computer.

Design. Upon arrival in the laboratory, the subjects were arbitrarily assigned to one of four groups arising from crossing modality of the to-be-remembered items with abstract or concrete word pool. Both the abstract and concrete groups saw a different set of six words on each trial. The subjects in the auditory groups pronounced the words out loud, whereas those in the visual groups read the words silently. An experimenter ensured that the subjects followed instructions. The words were displayed for $1 \mathrm{sec}$ in 18-point Geneva bold inverse against a black background in the center of the CRT. The distractor task was to verify addition problems. After each word was displayed, a random number between 1 and 5 was displayed, followed by two additional random numbers from the same range and the solution at a rate of one every $750 \mathrm{msec}$. The subject had $3 \mathrm{sec}$ after the appearance of the final addend in which to decide whether the computer's answer was true or false. The subjects responded by clicking with the mouse on an appropriately labeled button. Thus, each distractor period took $5.25 \mathrm{sec}$. Half the time the answer was true, one quarter of the time the answer was incorrect by \pm 1 , and one quarter of the time the answer was incorrect by \pm 2 . The reconstruction of order test was the same as in Experiment 1: The subject's task was first to click on any of the six "word" buttons and then to click on one of the "number" buttons to indicate which position the word had originally appeared in. Twenty seconds were allowed for the reconstruction of order. Each subject received 30 lists.

Procedure. The subjects were told that we were interested in how accurately they could perform two tasks simultaneously. It was emphasized that each task was equally important. One of the tasks was to remember the order of six words and the other was to solve addition problems. During the instructions, the subjects practiced re- sponding using the mouse, and no subject reported any difficulty with this method of responding. One practice trial was conducted with the experimenter watching, using six color names as the to-beremembered items for all subjects. The subjects were tested individually, were given a rest period approximately halfway through the experiment, and were allowed to adjust the monitor to a comfortable level of brightness.

\section{Results}

Distractor task performance. As in Experiment 1, the groups did not differ on the distractor task. For the auditory group, $90.6 \%$ of the problems were answered correctly with $2.7 \%$ omitted in the abstract condition; $92.9 \%$ were answered correctly with $2.0 \%$ omitted in the concrete condition. For the visual group, $92.7 \%$ of the problems were answered correctly with $3.0 \%$ omitted in the abstract condition, $92.5 \%$ were answered correctly with $2.1 \%$ omitted in the concrete condition. Analysis of the distractor task revealed no differences in performance as a function of modality $(F<1)$ or word type $[F(1,84)=$ $\left.1.97, M S_{\mathrm{e}}=.002, p>.15\right]$, and no reliable interaction $\left[F(1,84)=1.23, M S_{\mathrm{e}}=.002, p>.25\right]$.

Order reconstruction. Figure 3 shows the proportion of words correctly placed in order as a function of modality, stimulus type, and serial position. The proportion of items correctly placed in order was .338 in the auditory group and .375 in the visual group $[F(1,84)<1]$, revealing no overall advantage for either modality. However, there was a large effect of item type for both modalities. For the auditory modality, the proportion of items correctly placed in order was .407 for concrete and .268 for abstract words, and for the visual modality, the values were .461 for concrete and .269 for abstract. There was no interaction between presentation modality and type of word $[F(1,84)<1]$.

There was a main effect of position, reflecting the serial position function $\left[F(5,420)=28.46, M S_{\mathrm{e}}=0.006, p<\right.$ $.01]$, and a reliable interaction between modality and po-
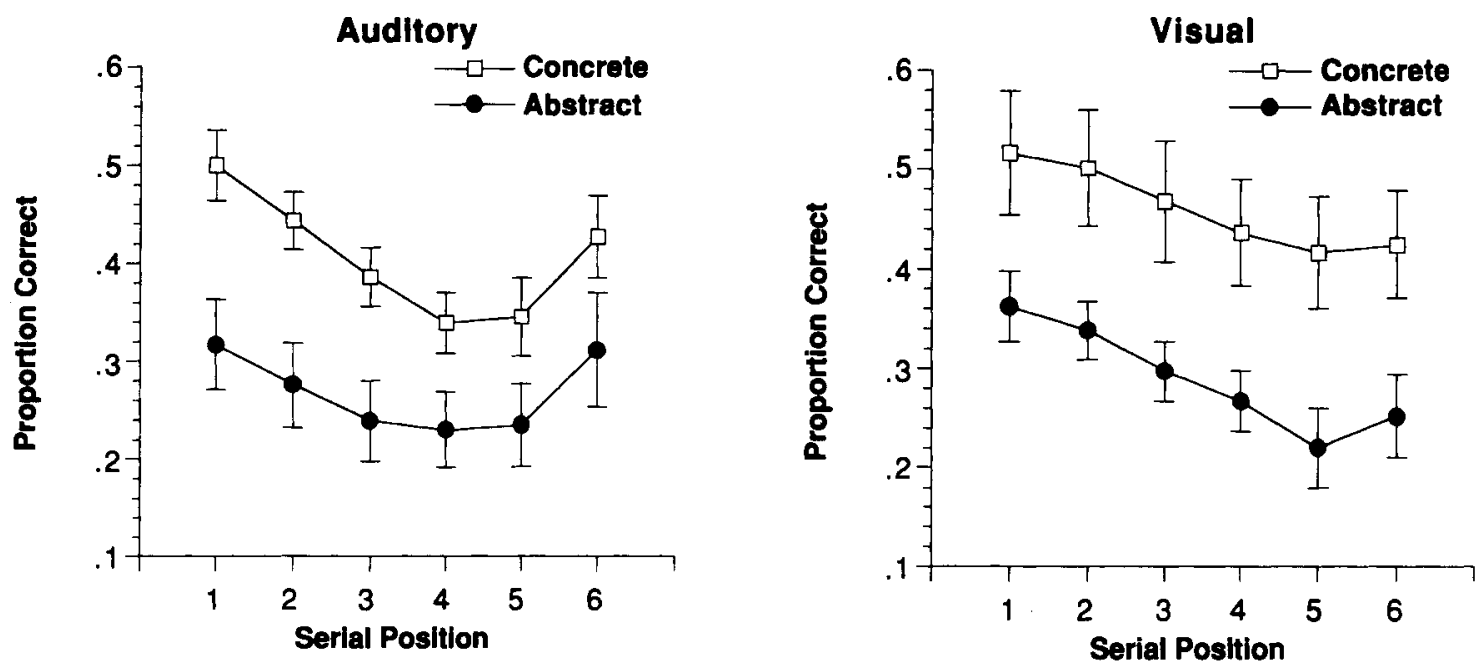

Figure 3. Proportion of words (and standard error of the mean) correctly placed in their presentation order as a function of input modality (visual or auditory), word type (abstract or concrete), and serial position in Experiment 2. 
sition, indicating the traditional modality effect $[F(5,420)$ $\left.=5.24, M S_{\mathrm{e}}=0.006, p<.01\right]$. There was no interaction between item type and serial position $[F(5,420)<1]$. Similarly, the three-way interaction between position, modality, and item type was not reliable $[F(5,420)=1.70$, $\left.M S_{\mathrm{e}}=0.006, p>10\right]$. Replicating Experiment 1, a modality effect was observed with a long-term free reconstruction of order task. Whereas Experiment 1 used a small set size (a pool of 18 letters), Experiment 2 had different items on each trial. In addition, Experiment 1 had an irregular presentation sequence, whereas in Experiment 2, the to-be-remembered items were presented according to a temporally regular pattern.

Perhaps more surprisingly, there was also a large effect of word type, with better order reconstruction for concrete words than for abstract words despite the fact that the subjects knew exactly which six words had been presented on any particular trial. Neither the dual-code (Paivio, 1969) nor the semantic association view (Jones, 1988) would predict this if the reconstruction of order task completely eliminated the role of item information.

\section{EXPERIMENT 3}

Experiments 1 and 2 demonstrated that presenting an item to a subject at test does not always serve as a complete reinstatement of all applicable item information. Experiment 3 was designed to test whether set size effects would be observable in a reconstruction of order task. In the small set-size condition, the same six items (the monosyllabic color names black, blue, brown, green, red, and white) occurred on every trial; in the large set-size condition, each trial contained six novel words that occurred only once during the entire experiment. At test, the subjects in both conditions were informed which six items had been presented on that particular trial and performed a free reconstruction of order test. As in the two previous experiments, modality of presentation was also varied.

\section{Method}

Subjects. Eighty-eight different Purdue University undergraduates volunteered to participate in exchange for credit in introductory psychology courses.

Design and Materials. Modality of presentation (auditory or visual) and set size (large or small) were between-subjects factors. Half of the subjects read the words aloud as they appeared, whereas the other half read the words silently. Half of the subjects received the same six items (the color names black, blue, brown, green, red, and white) in a different random order on each trial, whereas half of the subjects received a different set of six words (from Rubin \& Friendly, 1986) on each trial. Each word was displayed for $1 \mathrm{sec}$ in the center of the screen in 18-point Geneva bold black against a white background. The distractor task was implemented exactly as in Experiment 2. Thus, each list took $37.5 \mathrm{sec}$ to present. The subjects responded by clicking with the mouse on appropriately labeled buttons, as in Experiment 2. The subject's responses were displayed on the screen, but subjects were not told whether they had made the correct response. Twenty seconds were allowed for the reconstruction of order.

Procedure. The procedure was almost identical to that of Experiment 2. The subjects were unaware of the variables that were ma- nipulated, and they were allowed to adjust the monitor to comfortable levels of brightness. There was 1 practice trial (always using the color names) followed by 30 experimental trials, with a short break occurring halfway through. The subjects were tested individually in the auditory conditions, and either individually or in pairs in the visual conditions. An experimenter remained in the room to ensure that subjects complied with the instructions.

\section{Results and Discussion}

Distractor task performance. As in Experiments 1 and 2 , there were no statistically reliable differences in performance on the distractor tasks between groups. For the auditory group, $90.7 \%$ of the problems were answered correctly with $4.3 \%$ omitted in the small set-size condition; $89.5 \%$ were answered correctly with $3.4 \%$ omitted in the large set-size condition. For the visual group, $89.7 \%$ of the problems were answered correctly with $1.9 \%$ omitted in the small set-size condition; $89.0 \%$ were answered correctly with $5.2 \%$ omitted in the large set-size condition. An analysis of these data revealed no reliable differences (all $F \mathrm{~s}<1$ ).

Order reconstruction. Figure 4 shows the proportion of words correctly placed in order as a function of modality, stimulus set size, and serial position. The proportion of items correctly placed in order was .449 in the auditory group and .489 in the visual group $[F(1,84)<1]$, revealing no overall advantage for either modality. However, there was a reliable effect of set size. For the auditory modality, the proportion of items correctly placed in order was .486 for the small set size and .411 for the large set size, and for the visual modality, the values were .536 for the small set size and .442 for large set size.

As is apparent in Figure 4, there was a smaller effect of set size in the recency portion of the data, replicating previous results with serial recall (Manning \& Robinson, 1989), which led to a marginal interaction between set size and serial position $\left[F(5,420)=1.98, M S_{\mathrm{e}}=0.006\right.$, $.05<p<.10]$. Of the remaining interactions, only the modality $\times$ serial position interaction was reliable $[F(5,420)$ $\left.=22.36, M S_{\mathrm{e}}=0.006, p<.01\right]$, replicating the basic modality effect.

Once again, even though all of the items were presented to the subject, there was still an advantage for the final items in a list if the presentation modality was auditory rather than visual. More striking, however, was the advantage in performance when the same six items were repeated on every trial than when a unique set of items occurred on each trial, even though all items were presented at test to the subjects.

\section{GENERAL DISCUSSION}

Many researchers have assumed, either explicitly or implicitly, that presenting the to-be-remembered items to the subject at test eliminates the problem of potentially missing item information (e.g., Greene et al., 1988; Whiteman et al., 1994). Just as Tulving (1983) argued that presenting a copy of an item in a recognition test does not necessarily lead to the best retrieval cue, the three ex- 

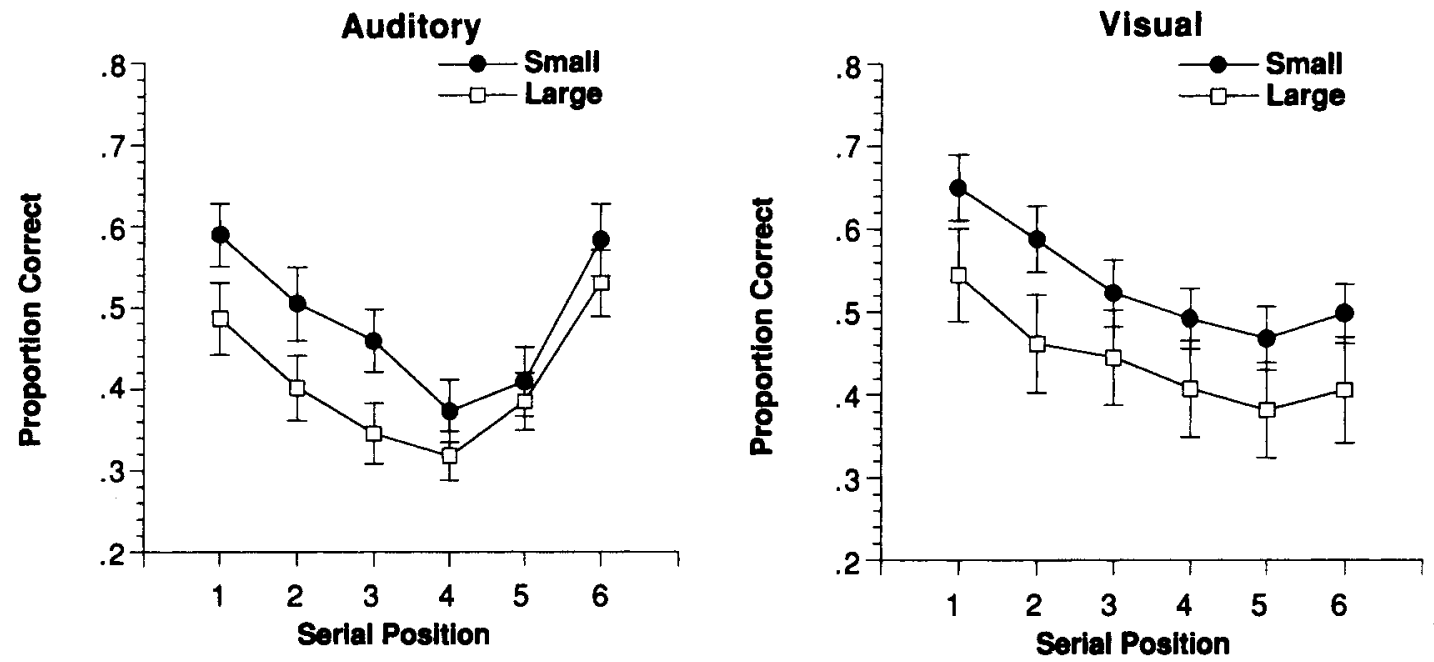

Figure 4. Proportion of words (and standard error of the mean) correctly placed in their presentation order as a function of input modality (auditory or visual), set size (small or large), and serial position in Experiment 3.

periments reported here suggest that the same is true in long-term free reconstruction of order tasks.

Although a free reconstruction of order task does not seem to require item information, the problem is similar to that encountered in prospective memory tasks. A person may intend to give Professor Smith a message the next time that he sees her, with the person serving as the retrieval cue. When he sees Professor Smith, the retrieval cue - a copy cue - is often not sufficient to retrieve the desired memory (cf. Robinson-Riegler, 1994). In every memory task that has been analyzed in detail, there is evidence that copy cues can fail to reinstate necessary information completely (Capaldi \& Neath, 1995). Even if one wanted to argue that the long-term free reconstruction of order task is nominally a pure measure of order memory because it does not, of itself, require the subject to remember item information, the present experiments suggest that nonetheless the subjects do remember and do use item information to complete the test. Because subjects use item information, the test is functionally not a pure measure of order memory.

Of the current theories of order memory, the one that can account most readily for these findings is Nairne's (1990) feature model. The model already accounts for many of the major effects seen with immediate serial recall, including modality and suffix effects, effects of phonological similarity and articulatory suppression, word-length effects (Neath \& Nairne, 1995), and differences between vowels and consonants (Surprenant \& Neath, 1996). The key aspect of the model is the retrieval process: the subject compares a degraded trace in primary memory with undegraded traces in secondary memory. Even if the test provides a copy cue, the subject must still perform this comparison. Thus, even though a test, such as long-term free reconstruction of order, may be nominally a pure test of order information, the psycho- logical processes used by the subject render the test impure. Effects of item information will be seen because the subject performs a discrimination based on an internal representation that includes item information $(\mathrm{Ca}-$ paldi \& Neath, 1995).

The modality effect was seen in the long-term free reconstruction of order tests used here because there was no overwriting of the modality-dependent features of the final item. Concrete items can be more richly encoded, and this can be captured in the feature model by increasing the range of values that each element can take; simply increasing the number of features does not improve performance (see Neath \& Nairne, 1995). Set size can also be incorporated: In the feature model, the probability of selecting the appropriate secondary memory trace as the match for a particular degraded primary trace is given by a variation of Luce's (1963) choice rule. If the denominator is increased, by allowing additional secondary memory traces to be considered, then the sampling probability will be lowered.

Regardless of the ultimate theoretical explanation, the main result of the three experiments should temper the conclusions drawn from previous work using long-term free reconstruction of order: Because presenting an item at test does not necessarily reinstate all appropriate item information in the internal representation, reconstruction of order tests do not offer a pure measure of order memory.

\section{REFERENCES}

ANDERSON, J. R., \& Bower, G. H. (1972). Recognition and retrieval processes in free recall. Psychological Review, 79, 97-123

BAHRick, H. P. (1970). Two-phase model for prompted recall. Psychological Review, 77, 215-222.

Capaldi, E. J., \& NEATH, I. (1995). Remembering and forgetting as context discrimination. Learning \& Memory, 2, 107-132.

Corballis, M. C. (1966). Rehearsal and decay in immediate recall of 
visually and aurally presented items. Canadian Journal of Psychology, 20, 43-51.

Crowder, R. G. (1970). The role of one's own voice in immediate memory. Cognitive Psychology, 1, 157-178.

Crowder, R. G. (1976). Principles of learning and memory. Hillsdale, $\mathrm{NJ}$ : Erlbaum

CrowDER, R. G. (1978a). Mechanisms of auditory backward masking in the stimulus suffix effect. Psychological Review, 85, 502-524.

Crowder, R. G. (1978b). Memory for phonologically uniform lists. Journal of Verbal Learning \& Verbal Behavior, 17, 73-89.

Crowder, R. G., \& Greene, R. L. (1987). On the remembrance of times past: The irregular list technique. Journal of Experimental Psychology: General, 116, 265-278.

CrowDER, R. G., \& MORTON, J. (1969). Precategorical acoustic storage (PAS). Perception \& Psychophysics, 5, 365-373.

Feenan, K., \& Snodgrass, J. G. (1990). The effect of context on discrimination and bias in recognition memory for pictures and words Memory \& Cognition, 18, 515-527.

GardinER, J. M., \& GREGG, V. H. (1979). When auditory memory is not overwritten. Journal of Verbal Learning \& Verbal Behavior, 18 , 705-719.

Geiselman, R. E., \& Glenny, J. (1977). Effects of imagining speakers' voices on the retention of words presented visually. Memory \& Cognition, 5, 499-504.

GLENBERG, A. M. (1987). Temporal context and memory. In D. S. Gorfein \& R. R. Hoffman (Eds.), Memory and learning: The Ebbinghaus Centennial Conference (pp. 173-190). Hillsdale, NJ: Erlbaum.

Greene, R. L., Elliott, C. L., \& Smith, M. D. (1988). When do interleaved suffixes improve recall? Journal of Memory \& Language, 27, 560-571.

HEALY, A. F. (1974). Separating item from order information in shortterm memory. Journal of Verbal Learning \& Verbal Behavior, 13 644-655.

Healy, A. F., Fendrich, D. W., Cunningham, T. F., \& Till, R. E. (1987). Effects of cuing on short-term retention of order information. Journal of Experimental Psychology: Learning, Memory, \& Cognition, 13, 413-425.

JONES, G. V. (1988). Images, predicates, and retrieval cues. In M. Denis, J. Englekamp, \& J. T. E. Richardson (Eds.), Cognitive and neuropsychological approaches to mental imagery (pp. 89-98). Dordrecht: Martinus Nijhoff.

KINTSCH, W. (1970). Learning, memory and conceptual processes. New York: Wiley.

Kučera, H., \& FranCIS, W. N. (1967). Computational analysis of presentday American English. Providence, RI: Brown University Press.

LUCE, R. D. (1963). Detection and recognition. In R. D. Luce, R. R. Bush, \& E. Galanter (Eds.), Handbook of mathematical psychology (pp. 103-189). New York: Wiley.

Manning, S. K., \& Robinson, I. I. (1989). Recency and suffix effects as a function of auditory confusability and set size. American Journal of Psychology, 102, 495-510.

MurRaY, D. J. (1966). Vocalization-at-presentation and immediate recall with varying recall methods. Quarterly Journal of Experimental Psychology, 18, 9-18.

NAIRNE, J. S. (1990), A feature model of immediate memory. Memory \& Cognition, 18, 251-269.

NaIRnE, J. S. (1991). Positional uncertainty in long-term memory. Memory \& Cognition, 19, 332-340.

NAIRNE, J. S. (1992). The loss of positional certainty in long-term memory. Psychological Science, 3, 199-202.

NajRne, J. S., \& NeumanN, C. (1993). Enhancing effects of similarity on long-term memory for order. Journal of Experimental Psychology: Learning, Memory, \& Cognition, 19, 329-337.

NEATH, I. (1993). Contextual and distinctive processes and the serial position function. Journal of Memory \& Language, 32, 820-840.

Neath, I., \& Crowder, R. G. (1990). Schedules of presentation and temporal distinctiveness in human memory. Journal of Experimental Psychology: Learning. Memory, \& Cognition, 16, 316-327.

NEATH, I., \& NAIRNE, J. S. (1995). Word-length effects in immediate memory: Overwriting trace decay theory. Psychonomic Bulletin \& Review, 2, 429-441.

Neath, I., Surprenant, A. M., \& Crowder, R. G. (1993). The contextdependent stimulus-suffix effect. Journal of Experimental Psychology: Learning, Memory, \& Cognition, 19, 698-703.

PaIvio, A. (1969). Mental imagery in associative learning and memory. Psychological Review, 76, 241-263.

Paivio, A., Yuille, J. C., \& Madigan, S. A. (1968). Concreteness, imagery, and meaningfulness values for 925 nouns. Journal of Experimental Psychology Monographs, 76(1, Pt. 2), 1-25.

PENNEY, C. G. (1989). Modality effects and the structure of short-term verbal memory. Memory \& Cognition, 17, 398-422.

ROBINSON-RIEGLER, M. B. (1994). The recognition-recall hypothesis of event-based prospective memory. Unpublished doctoral dissertation, Purdue University.

Rubin, D. C., \& Friendly, M. (1986). Predicting which words get recalled: Measures of free recall, availability, goodness, emotionality, and pronunciability for 925 nouns. Memory \& Cognition, 14, 79-94

SCHAB, F. R., \& Crowder, R. G. (1989). Accuracy of temporal coding Auditory-visual comparisons. Memory \& Cognition, 17, 384-397.

Surprenant, A. M., \& Neath, I. (1996). The relation between discriminability and memory for vowels, consonants, and silent-center vowels. Memory \& Cognition, 24, 356-366.

Surprenant, A. M., Pitt, M. A., \& Crowder, R. G. (1993). Auditory recency in immediate memory. Quarterly Journal of Experimental Psychology, 46A, 193-223.

Tulving, E. (1983). Elements of episodic memory. New York: Oxford University Press.

WashburN, M. F. (1916). Movement and mental imagery. Boston: Houghton Mifflin

WATKINS, M. J., \& GARDINER, J. M. (1979). An appreciation of generaterecognize theory of recall. Journal of Verbal Learning \& Verbal Behavior, 18, 687-704

Watkins, M. J., LeCompte, D. C., Elliott, M. N., \& Fish, S. B. (1992). Short-term memory for the timing of auditory and visual signals. Journal of Experimental Psychology: Learning, Memory, \& Cognition, 18, 931-938.

WATKINS, O. C., \& WatKINS, M. J. (1980). The modality effect and echoic persistence. Journal of Experimental Psychology: General, 109, 251-278.

Whiteman, H. L., Nairne, J. S., \& Serra, M. (1994). Recognition and recall-like processes in the long-term reconstruction of order. $\mathrm{Mem}$. ory, 2, 275-295.

\section{NOTES}

1. There is a third major theory, precategorical acoustic store or PAS (Crowder, 1978a; Crowder \& Morton, 1969). This view assumes that auditory to-be-remembered items are stored in a relatively uncategorized code for brief periods of time. Newly entering items interfere with already present items, but only if the new items are acoustically similar to the previous items. Despite the popularity of that view, many studies demonstrate the problems with PAS (e.g., Neath, Surprenant, \& Crowder, 1993; Surprenant, Pitt, \& Crowder, 1993), which include its in ability to account for long-term modality effects. Because the studies here used long-term free reconstruction of order, PAS is not considered a viable explanation.

2. Pattern 1, which had the worst performance, may be characterized as being an increasing schedule of presentation: the shortest duration occurred first; the longest duration occurred last. This finding is consistent with predictions of the dimensional distinctiveness model (Neath 1993; Neath \& Crowder, 1990). There were no reliable interactions [al $F_{\mathrm{S}}<1$, except for the modality $\times$ signal interaction, $F(1,42)=1.98$, $p>.15$; and the modality $\times$ signal $\times$ pattern interaction, $F(3,126)=$ $1.24, p>.25]$.

(Manuscript received April 6, 1995; revision accepted for publication January 3,1996 .) 